\title{
Reflexões acerca da adesão aos exercícios físicos: comportamento de risco ou vulnerabilidade?
}

\author{
Alexandre Palma ${ }^{l}$ \\ Lyana Cardoso Salomão ${ }^{2}$ \\ André Gustavo Nicolodi ${ }^{3}$ \\ Alberto Caldas ${ }^{4}$
}

\begin{abstract}
Resumo: 0 objetivo do presente estudo foi refletir sobre as relações entre o estado de vulnerabilidade e a adesão aos exercícios físicos na cidade do Rio de Janeiro. Para tanto, foram levantados dados sobre as características de 5.457 indivíduos que procuraram e iniciaram exercícios físicos em academias de ginástica; dados referentes à condição de miserabilidade na cidade; e dados referentes ao índice de Desenvolvimento Humano da cidade do Rio de Janeiro. Além disso, foram entrevistados sete indivíduos, sendo dois obesos, dois com histórico de doença cardiovascular e três idosos. Os resultados mostram que mais do que um comportamento de risco, as pessoas podem estar numa situação de vulnerabilidade, onde não conseguem aderir à prática de exercícios físicos. Palavras-chave: Vulnerabilidade, Comportamento de Risco, Adesão aos Exercícios Físicos.
\end{abstract}

Diversos têm sido os estudos que destacam a influência da prática de exercícios físicos sobre a incidência ou prevalência de doenças (Paffenbarger et al., 1986; Berlin et ai, 1990; Pate et al., 1995). Estes estudos têm demonstrado que o sedentarismo é

1 Doutor em Saúde Pública. Docente da Universidade Gama Filho e da Universidade Estácio de Sá. Coordenador do Salus - Grupo de Estudos em Educação Física e Saúde da Universidade Gama Filho.

2 Graduada em Educação Física pela Universidade Estácio de Sá.

3 Graduado em Educação Física pela Universidade Gama Filho

Movimento Porto Alegre, v.9, n. 3, p 83-100, set./dez. de 2003 
um fator de risco importante ao desenvolvimento de diferentes doenças, e mais especificamente, às doenças cardiovasculares.

A noção de fator de risco, por outro lado, significa em última instância as circunstâncias do ambiente ou as características pessoais que conferem a um dado indivíduo a maior probabilidade matemática para o desenvolvimento de determinada doença (Pereira, 1995). Deste modo, as chances de adoecimento poderiam ser calculadas mediante aplicação da ferramenta epidemiológica. Goldberg (1994) sustenta que tradicionalmente as variáveis independentes são consideradas na análise estatística e resultam numa listagem de "fatores de risco". Os métodos estatísticos empregados buscam, então, evidenciar uma ligação entre as variáveis e a ocorrência do fenômeno estudado, medir a forma e a intensidade desta ligação e, assim, estabelecer uma associação causai. De fato, lembra o autor, como a presença de uma causa exige que o efeito exista e quando suprimida que o efeito desapareça, substituíram o termo "causa" por uma definição de probabilidade (fator de risco), onde o efeito tende a aumentar quando a causa está presente.

Neste sentido, e considerando a visão estreita de saúde como ausência de doenças, tem sido difundida a idéia de "grupos de risco" e "comportamentos de risco". O estabelecimento, através de estudos descritivos, da associação entre determinados grupos e a ocorrência de doenças traz a idéia de grupo de risco. O conceito de comportamento de risco, por outro lado, diz respeito aos hábitos, atitudes e/ou situações que se associam à presença de doenças, isto é, refere-se às atitudes pessoais inadequadas, as quais aumentam as chances de ocorrência da doença.

Atualmente, a epidemiologia, sem desconsiderar o modelo médico e os tratamentos estatísticos, também tem levado em conta variáveis sócio-econômicas. Deste modo, categorias como rendimento, grau de instrução, sexo, estado civil, situação profissional, etc. têm sido incluídas como variáveis importantes. Contudo, segundo Goldberg (1994), as vias pelas quais as condições sócio-econômicas influem sobre a saúde são múltiplas e diferenciadas. Por vezes, as análises que consideram esta dimensão, o fazem seguindo o mesmo modelo epidemiológico e acabam por realizar análises simplistas, uma vez que desconsideram os fenômenos fundamentais dos mecanismos sociais, bem como sua historicidade. Goldberg (1994, p. 98) explica que ao se considerar os individuos como unidades estatísticas independentes, ignora-se 
completamente a existência das relações sociais nas quais as representações, os comportamentos, os saber es e os modos de vida são produzidos.

Considerando o exposto, é possível empreender uma apreciação crítica, cujo foco não se concentra no sujeito, no biológico, ou nas causas e efeitos, mas, antes, na vulnerabilidade do coletivo e do indivíduo, nas contradições da sociedade, bem como nas múltiplas relações que estas interagem com a prática de exercícios físicos.

Dentro desta perspectiva, o presente estudo tem como objetivo refletir sobre as relações entre o estado de vulnerabilidade e a adesão aos exercícios físicos na cidade do Rio de Janeiro.

Para tanto, foram levantados dados sobre as características de 5.457 indivíduos que procuraram e iniciaram exercícios físicos em academias de ginástica; dados referentes à condição de miserabilidade na cidade; e dados referentes ao índice de Desenvolvimento Humano da cidade do Rio de Janeiro. Além disso, foram entrevistados sete indivíduos, sendo dois obesos, dois com histórico de doença cardiovascular e três idosos.

\section{Vulnerabilidade}

O elemento de composição "vulner" origina-se do latim vulnus, o qual significa ferida. Vulnerável, então, é considerado o estado de estar sujeito a ser derrotado, prejudicado ou ofendido. É possível pensar numa vulnerabilidade individual, isto é, um estado ou condição particular de um indivíduo que o torna vulnerável. Tome-se como exemplo uma criança que não foi vacinada contra a poliomielite. Caso houvesse a exposição desta criança ao vírus causador da doença, suas chances de desenvolver a doença seriam maiores do que outras que receberam vacinas. A vulnerabilidade pode ser também biológica. Atualmente é aceito que, no nível biológico, todas as pessoas são vulneráveis à infecção pelo HIV Isto é, ao contato com o sangue ou sêmen as pessoas teriam grandes chances de se tornarem soropositivas (Mann et ai, 1993). Pode-se, ainda, falar em vulnerabilidade geográfica. As condições climáticas extremas, os eventos como terremotos e furacões, a proximidade de regiões perigosas como os vulcões, por exemplo, podem criar um ambiente propício ao aparecimento de desastres ou condições adversas (Horlick-Jones, 1992). 
Contudo, a história da saúde pública é repleta de exemplos onde o tecido social provocou alguma deterioração nos mecanismos de defesa e, consequentemente, resultou em problemas epidemiológicas. Os estudos de Snow, Virchow, Engels, entre outros, enfatizaram bem esta questão da vulnerabilidade que certos grupos sociais apresentavam em relação à saúde. Deste modo, a vulnerabilidade pode manifestar-se não só em decorrência das condições individuais, biológicas e/ou geográficas, mas também e, talvez sobretudo, das condições sociais de vida desfavoráveis.

Um grande número de trabalhos sobre vulnerabilidade revela a importância das condições sócio-econômicas em gerar susceptibilidade aos eventos perigosos. Entretanto, pode-se destacar, também, a vulnerabilidade das mulheres, idosos, crianças, pessoas com deficiências a qualquer situação de risco ou estado em que estes grupos encontram-se enfraquecidos.

As diversas apreciações sobre o conceito de vulnerabilidade, apresentadas por Horlick-Jones (1992), conduzem a duas concepções generalizadas. Por um lado, tratam a vulnerabilidade como uma erosão do poder de reação de um determinado sistema às perturbações geradas pela interação entre este mesmo sistema e o ambiente. Por outro, expõem a suscetibilidade que determinados grupos, apresentam à aparição das perturbações.

Mann et ai (1993), ao comentarem sobre o risco de infecção pelo Hiy explicam que o HIV necessita de ações/comportamentos específicos para que ocorra a transmissão do vírus. Assim, o comportamento individual seria fundamental à infecção pelo HIV Porém, o que os autores propõem é considerar, na avaliação da vulnerabilidade, os fatores presentes na comunidade que podem influenciar a vulnerabilidade pessoal. É desta forma, que suscita a importância da "vulnerabilidade coletiva" (ou social).

Pensar em vulnerabilidade social remete, de imediato, ao conceito de "exclusão social". A noção de "exclusão social" tem sido fortemente associada ao crescente desemprego surgido nas últimas décadas, em virtude, principalmente, das alterações ocorridas na economia internacional. Vários autores, porém, procuram não ficar presos a este entendimento e avançam ao considerarem outros aspectos relevantes.

Dupas (1999), por exemplo, revê o conceito do termo, mas o delimita, para seu estudo, com um enfoque sobre a pobreza, a 
qual ele considera a principal dimensão da exclusão, uma vez que aquela dificulta o acesso real aos serviços e bens de consumo julgados adequados a uma sobrevivência digna. Sob este olhar, a literatura parece concordar que, após a segunda grande guerra, instalou-se nos países centrais o estado de bem-estar, o qual não deve ser encarado como "caridade" ou "fornecimento de donativos individuais", mas do contrário, como um direito do cidadão, como uma forma de "seguro coletivo" (Bauman, 1998). Apesar de alguns autores argumentarem que o fenômeno não é de todo uma novidade na história, o processo denominado de globalização vem sendo apontado como um importante condutor da maior vulnerabilidade dos grupos desprivilegiados, além, do descompromisso do estado com o bemestar social (Navarro, 1998; Kurz, 1997 e Dupas, 1999).

Definir o termo "exclusão social" por um aspecto estritamente econômico parece não ser adequado. Demo (1998) frisa que a pobreza material é sempre marcante, mas que o processo de exclusão passaria pela perda do senso de pertencimento, uma vez que os indivíduos experimentariam um abandono geral, além da incapacidade de reagir.

Pode-se, então, considerar que de fato os excluídos carecem dos bens e serviços necessários, mas para além disto é preciso considerar, também, que o cerne da questão passa pela precariedade da cidadania. Bauman (1998) coloca o dedo na ferida e lembra que os "excluídos" são tratados pela sociedade como "estranhos", os quais foram negados os recursos de construção da identidade e, deste modo, os instrumentos da cidadania. $\mathrm{O}$ aspecto político da exclusão revela que seu maior problema é a falta de cidadania, que impede os excluídos de perceberem como as carências são impostas e as oportunidades obstruídas.

Demo (1998) comenta, ainda, que a inserção pode ser um modo elegante de exclusão. Ao buscar soluções assistencialistas ou de inserção ao percurso de privação, os indivíduos continuam desafiliados, desqualificados, inválidos, dissociados, porque na grande maioria das vezes não é atendida a questão dos direitos humanos. Em outras palavras, parece que as soluções assistencialistas cumprem um papel de tolerância ao outro.

No rastro deste debate, Santos (1999) lembra que a emancipação dos excluídos não perpassa só o caminho da política e da economia, mas é, antes, individual, social e cultural. Segun- 
do o sociólogo, para abolir as formas de opressão e exclusão social não basta conceder os direitos, é preciso, também, organizar a reconversão dos processos de socialização e de inculcação cultural.

Outra revisão do conceito de vulnerabilidade foi elaborada por Delor e Hubert (2000). Os autores reconhecem, de imediato, a ambigüidade do uso do termo "vulnerabilidade" e a importância de conceituá-lo mais precisamente, sob o risco deste perder sua capacidade heurística. Dentre os trabalhos, por eles, revisados encontra-se o de Watts e Bothe, o qual traz à tona o entendimento de "espaço de vulnerabilidade", onde manifestam-se três coordenadas de vulnerabilidade: o risco de estar exposto a situações de crise (exposição); o risco de não ter recursos necessários para lutar contra estas situações (capacidade); e, o risco de estar sujeito a sérias conseqüências como resultado das crises (potencialidade). Estes espaços estão superpostos e acabam por reforçar a vulnerabilidade individual. Deste modo, os indivíduos não têm a mesma vulnerabilidade em diferentes contextos.

A definição do conceito de vulnerabilidade nos estudos sobre doenças infecto-contagiosas, no entanto, é apresentada por Delor e Hubert (2000), a partir de três níveis: o primeiro nível refere-se à "trajetória social", onde cada indivíduo segue diferentes fases de sua trajetória de vida. Este nível se relaciona ao curso individual da vida, idade, identidade, projeto de vida etc. O segundo nível, "cruzamento", ocorre na interação entre duas "trajetórias". De fato, lembram os autores, a infecção requer que no mínimo dois indivíduos e, deste modo, duas trajetórias se encontrem. O terceiro e último nível é imputado ao "contexto social". Este nível influencia o momento, as decisões em jogo e as formas de encontros entre as diferentes trajetórias. Embora nas doenças denominadas crônico-degenerativas seja difícil verificar o segundo nível, cabe aqui destacar a importância do contexto social, cultural e econômico que apresenta e facilita o modo sedentário de viver, o uso de cigarro, a alimentação gordurosa e/ ou altamente calórica.

Em recente trabalho, Ayres et ai (2003) ponderaram que o termo vulnerabilidade é originário da área dos Direitos Universais Humanos e designa grupos ou indivíduos fragilizados, tanto jurídico quanto politicamente, na promoção, proteção ou garantia de seus direitos como cidadão. Segundo os autores, na saúde 
a expressão penetrou mais avidamente a partir do trabalho de Mann et al (1993). Assim, a emergência da vulnerabilidade como referência conceituai tem representado um passo importante na construção de conhecimentos e intervenções em saúde pública, uma vez que facilita a identificação das razões últimas da epidemia e seus impactos nas coletividades, as quais apresentam suscetibilidade orgânica, modos de organização do sistema de saúde, aspectos comportamentais, culturais e econômicos, etc.

Por outro lado, Ayres et ai (2003) trazem, ainda, uma importante discussão envolvendo a questão do risco. A confusão dos termos "risco" e "vulnerabilidade", segundo os autores, tem contribuído para causar confusão. Risco busca exprimir as chances matemáticas de adoecimento, onde as associações estatísticas entre eventos patológicos e não-patológicos tenta reconhecer fatores causadores da doença. De outro modo, a vulnerabilidade expressa a potencialidade para o adoecimento em um indivíduo que vive em um determinado conjunto de condições. Os autores identificara, deste modo, os modelos conceituais presentes nas práticas intervencionistas e suas repercussões sobre o processo saúde-doença.

Neste sentido, o modelo conceituai baseado na compreensão de "grupos de risco" buscaria impedir o contato entre o indivíduo e o agente que proporciona o agravo à saúde. Este modelo, no entanto, acaba por estigmatizar, discriminar as próprias vítimas. Na mesma perspectiva, o conceito de "comportamento de risco" surge com a identificação das atitudes associadas à presença da doença. O comportamento é, então, identificado como a exposição ao agravo e resolvido com as práticas ditas seguras. Contudo, o tempo tem mostrado que sua grande dificuldade reside na culpabilização dos indivíduos, isto é, se a doença pode ser evitada por uma atitude pessoal, a sua ocorrência só pode advir por irresponsabilidade do próprio indivíduo. Além disto, nos dois casos a grande debilidade destas abordagens situa-se no entendimento de que o objeto de estudo é o fator de risco ou a doença e não os grupos humanos (Goldberg, 1994). Por outro lado, o modelo conceituai centrado na "vulnerabilidade" tem como problema-alvo as suscetibilidades populacionais.

Para Kaplan (1996) existe um substancial corpo de evidências que demonstram a forte associação inversa entre as classes sociais e os efeitos sobre a saúde. Contudo, o autor chama a atenção de que o foco de análise deve considerar as característi- 
cas da comunidade em que as pessoas vivem, ao invés dos atributos individuais que indicam as condições sócio-econômicas. Os fatores de risco sócio-ambientais e pessoais aglomeram-se nos espaços sociais, de tal modo que são importantemente relacionadas a todas as mortalidades. Kaplan demonstra, então, uma série de fatores associados com as taxas padronizadas de mortalidade, a partir de dados de residentes na Califórnia (EUA). As "odds ratios" (razões de chances) entre os fatores e as altas e baixas mortalidades foram: baixa educação $(4,25)$; incapacidade de realizar R $(4,0)$; obesidade $(3,1)$; insegurança na vizinhança $(2,75)$; baixo suporte emocional $(2,6)$; sedentarismo $(2,3)$; baixo salário $(2,3)$; alimentação inadequada $(1,6)$; e, hábito de fumar $(1,5)$.

\section{O caso da cidade do Rio de Janeiro}

As reflexões acerca da adesão das pessoas à prática de exercícios físicos têm se baseado no modelo conceituai dos comportamentos de risco. O Programa Agita São Paulo (1998), por exemplo, destaca logo em sua apresentação as associações entre o sedentarismo e a ocorrência de diferentes doenças e muito timidamente, numa única linha, comenta sobre a ligação entre sedentarismo e nível sócioeconômico. Cabe, aqui, destacar que esta relação anunciada no Programa segue uma tendência dos estudos em epidemiologia de levar em consideração nas análises as variáveis sócio-econômicas, sem desconsiderar o modelo médico e os tratamentos estatísticos. Contudo, como lembra Goldberg (1994), as relações entre as condições sócioeconômicas e suas influências sobre a saúde são múltiplas e diferenciadas. Ao realizar a análise matemática dos dados, por vezes, se desconsidera fenômenos importantes dos mecanismos sociais. A intenção dos idealizadores do Programa é estendê-lo ao Brasil (Agita Brasil) e a outras cidades (Agita Rio, por exemplo). Entretanto, é interessante ressaltar que o berço do Programa é a cidade de São Caetano do Sul, cidade em primeiro lugar no ranking do índice de Desenvolvimento Humano (IDH) das cidades brasileiras (Pochmann e Amorim, 2003).

Não obstante a cidade do Rio de Janeiro ocupe a $17^{\mathrm{a}}$ posição do ranking do IDH, é imprescindível considerar as próprias desigualdades internas da cidade. Na série de reportagens iniciadas 
em 24 de março de 2001 e denominada de "Retratos do Rio", o jornal O Globo apresentou uma síntese do primeiro Relatório de Desenvolvimento Humano de um município, não publicado, realizado pelo Instituto de Pesquisa Econômica Aplicada (IPEA). Nele consta que o bairro da Lagoa atinge o IDH de 0,902 comparável ao da Itália e que Acari apresenta um IDH de 0,573 semelhante aos países africanos. Do total de bairros, apenas 34 foram considerados de alto desenvolvimento humano (acima de 0,800). O médio-alto desenvolvimento humano (IDH entre 0,700 e 0,800 ) atingiu 69 bairros. 52 bairros foram considerados de médio desenvolvimento humano (IDH entre 0,600 e 0,699). O médio-bai-xo desenvolvimento humano (abaixo de 0,600) atingiu seis bairros. O relatório ainda aponta que 90 bairros, que somam uma população total de 3,23 milhões de pessoas ( $60 \%$ da população) ficaram abaixo do IDH médio da cidade $(0,744)$.

O relatório da pesquisa "Mapa do fim da fome da população total - 2003" divulgado pelo IBGE (2003) aponta que a condição de rrriserabilidade é atingida quando alcança a linha de $\mathrm{R} \$ 79,00$. Isto é, quando a renda familiar dividida pelo número total de membros encontra-se até o referido valor. E significa que aqueles indivíduos não terão recursos para consumir a quantidade suficiente de calorias para viver em condições aceitáveis (sic). Este mesmo relatório mostra que, do total da população carioca, 878.560 pessoas $(14,57 \%)$ estão abaixo desta linha.

Szwarcwald et al. (1999) observaram correlações significativas entre a desigualdade de renda e as condições de saúde no município do Rio de Janeiro. Os autores utilizaram os indicadores de distribuição de renda (índice de Gini e de Robin-Hood) e sócio-demográficos (taxa de analfabetismo, índice de pobreza, renda média, densidade demográfica e da população favelada, etc.) para confrontarem com os indicadores de saúde (coeficiente de mortalidade infantil, mortalidade padronizada por idade, esperança de vida ao nascer e taxa de homicídios). Todos os indicadores de saúde mostraram-se, então, significativamente correlacionados aos indicadores de desigualdade de renda. A tabela 1 apresenta alguns destes dados. 
Tabela 1. Indicadores sócio-ecomômicos e de saúde segundo as regiões administrativas do município do Rio de Janeiro, 1991

\begin{tabular}{|c|c|c|c|c|}
\hline \multirow[b]{2}{*}{$\begin{array}{c}\text { Região } \\
\text { Administrativa }\end{array}$} & \multicolumn{4}{|c|}{ Indicadores } \\
\hline & $\begin{array}{c}\text { Taxa de } \\
\text { analfabetismo } \\
\text { (\%) }\end{array}$ & $\begin{array}{c}\text { Renda média } \\
\text { (em salários } \\
\text { mínimos) }\end{array}$ & $\begin{array}{c}\text { Densidade de } \\
\text { populaçāo } \\
\text { favelada (hab/ha) }\end{array}$ & \begin{tabular}{|c|} 
Taxa de \\
homicídios \\
por 100.000 \\
habitantes \\
\end{tabular} \\
\hline 1- Portuária & 12,9 & 2,7 & 20,1 & 288,3 \\
\hline II-Centro & 4,1 & 4,6 & 0,0 & 155,9 \\
\hline III - Alo Comprido & 8,0 & 4,4 & 38,0 & 273,8 \\
\hline IV - Botafogo & 2,4 & 12,2 & 8,6 & 50,0 \\
\hline V-Copacabana & 2,6 & 12,3 & 15,8 & 48,2 \\
\hline $\mathrm{VI}$ - Lagoa & 7,0 & 16,3 & 25,6 & 76,6 \\
\hline VII - São Cristovão & 10,3 & 3,1 & 46,6 & 170,9 \\
\hline VIII - Tijuca & 3,6 & 10,1 & 6,2 & 113,8 \\
\hline IX-Vila Isabel & 3,9 & 8,8 & 16,6 & 93,4 \\
\hline$\underline{x-\text { Pamos }}$ & 13,6 & 2,9 & 70,9 & 194,9 \\
\hline XI-Penha & 8,5 & 3,2 & 24,5 & 212,7 \\
\hline XII - Inhaúma & 10,0 & 3,1 & 52,2 & 261,2 \\
\hline XIII - Méier & 4,1 & 5,5 & 12,0 & 57,5 \\
\hline XIV - Irajá & 5,1 & 4,2 & 16,2 & 227,6 \\
\hline XV-Madureira & 6,6 & 3,5 & 12,5 & 124,2 \\
\hline XVI- Jacarepaguá & 7,8 & 5,2 & 4,6 & 126,7 \\
\hline XVII - Bangu & 9,0 & 3,0 & 6,1 & 174,4 \\
\hline XVIII - Campo Grande & 10,0 & 3,1 & 0,8 & 123,1 \\
\hline XIX - Santa Cruz & 11,1 & 2,4 & 1,0 & 155,6 \\
\hline XX - 1. do Governador & 6,8 & 6,2 & 11,5 & 105,6 \\
\hline XXI-1. de Paquetá & 9,7 & 4,4 & 0,0 & 0,0 \\
\hline XXII-Anchieta & 9,1 & 2,8 & 21,7 & 387,0 \\
\hline XXIII - Santa Cruz & 7,2 & 5,1 & 15,6 & 107,0 \\
\hline XXIV - Barra da Tijuca & 6,8 & 18,1 & 0,8 & 37,8 \\
\hline
\end{tabular}

Movimento Porto Alegre, v.9, n. 3, p.83-100, set./dez. de 2003 
É importante considerar a elevada taxa de violência urbana em várias regiões da cidade e suas relações com o sedentarismo, uma vez que alguns estudos têm apontado para a associação entre a violência urbana e o sedentarismo (Craig et al., 2002; CDC, 2003).

O que se traz para a arena do debate, então, é: a) como engajar grande parte da população carioca num programa de promoção de exercícios físicos e saúde frente a estas situações?;

b) qual a quantidade que se espera de adesão da população?; e,

c) diante do quadro de miserabilidade e indigência apresentado, qual a emergência e relevância de um programa de promoção de exercícios físicos e saúde?

Afora a Zona Sul e alguns outros poucos pontos da cidade, existe uma quantidade pequena de espaços físicos adequados, seguros e agradáveis para a realização de exercícios físicos na cidade. O Rio de Janeiro, embora comporte um imaginário esportivo, nãp dispõe de muitos locais com policiamento permanente, com instalações adequadas, longe do trânsito e da poluição dos veículos, enfim, locais que reunam condições satisfatórias para a prática de exercícios.

Assim, a academia de ginástica tem sido considerado o local mais apropriado para a população manter-se fisicamente ativa. Mas nem tanto! Num levantamento realizado com 5.457 indivíduos que estavam entrando nas academias de ginástica na cidade do Rio de Janeiro pôde-se observar novos estados de vulnerabilidade, ou seja, as pessoas que entram nas academias pertencem a grupos bem característicos, enquanto outros grupos parecem excluídos deste processo.

O grupo etário que mais procura as academias situa-se entre 20 a 29 anos $(32,96 \%)$ A tabela 2 apresenta estes dados.

Movimento Porto Alegre, v.9, n. 3, p.83-100, set./dez. de 2003 
Tabela 2. Distribuição do número de indivíduos que estão entrando nas academias de ginástica, em função da faixa etária

\begin{tabular}{|c|c|c|c|c|c|c|}
\hline & \multicolumn{2}{|c|}{ Total } & \multicolumn{2}{|c|}{ Masculino } & \multicolumn{2}{|c|}{ Feminino } \\
\hline Faixa Etária & $\mathbf{n}$ & $\%$ & $\mathbf{n}$ & $\%$ & $\mathbf{n}$ & $\%$ \\
\hline 10a14 & 83 & 1,5 & 60 & 2,7 & 23 & 0,7 \\
\hline $15 \mathrm{a} 19$ & 590 & 10,8 & 258 & 11,5 & 332 & 10,3 \\
\hline 20 a 24 & 936 & 17,2 & 389 & 17,4 & 547 & 17,0 \\
\hline 25 a 29 & 863 & 15,8 & 379 & 17,0 & 484 & 15,0 \\
\hline 30 a 34 & 602 & 11,0 & 306 & 13,7 & 296 & 9,2 \\
\hline 35 a 39 & 566 & 10,4 & 220 & 9,8 & 346 & 10,7 \\
\hline 40 a 44 & 454 & 8,3 & 149 & 6,7 & 305 & 9,5 \\
\hline 45 a 49 & 455 & 8,3 & 143 & 6,4 & 312 & 9,7 \\
\hline 50 a 54 & 385 & 7,1 & 96 & 4,3 & 289 & 9,0 \\
\hline 55 a 59 & 208 & 3,8 & 79 & 3,5 & 129 & 4,0 \\
\hline 60 a 64 & 146 & 2,7 & 80 & 3,6 & 66 & 2,0 \\
\hline 65 a 69 & 58 & 1,1 & 29 & 1,3 & 29 & 0,9 \\
\hline 70 a 74 & 64 & 1,2 & 21 & 0,9 & 3 & 1,3 \\
\hline 75 a 79 & 29 & 0,5 & 15 & 0,7 & 14 & 0,4 \\
\hline mais de 80 & 18 & 0,3 & 10 & 0,4 & 8 & 0,2 \\
\hline total & 5457 & & 2234 & & 3223 & \\
\hline
\end{tabular}

Ao que parece as academias não são espaços para os idosos. Segundo a antropóloga Stéphane Malysse (2002), como as relações sociais tem sido utilitárias, o ideal de beleza assumiu um valor de mercado e o corpo é a "moeda", um fetiche que se vende, se constrói e circula. A autora, ainda, comenta que há uma ordenação hierárquica da corpolatria a partir da inter-rela-ção das categorias estéticas representadas por sinais físicos, tais como os músculos, cor da pele, juventude, etc. e das qualidades sociais da aparência. Assim, esses códigos (branco/preto, gordo/ esbelto, musculoso/magro, jovem/velho) são recontextualizados pelas ideologias da juventude, dos exercícios físicos, da magre-za, do gênero, etc.

Dentro desta mesma perspectiva, Sabino (2002) também aponta para a hierarquização entre os praticantes de exercícios físicos nas academias. Entre os homens gozam de mais prestígio os "fisiculturistas" e os "veteranos". Os primeiros são aqueles de grande massa muscular, enquanto os segundos referem-se

Movimento Porto Alegre, v.9, n. 3, p.83-100, set./dez. de 2003 
àqueles com vasta experiência na prática de exercícios e massa muscular considerável, mas não exagerada. Os "comuns" são aqueles que, embora sendo maioria, não gozam de prestígio, uma vez que não têm capital de competência nem capital corporal. Entre as mulheres, o autor identifica os mesmos tipos, contudo as "fisiculturistas" não gozam de prestígio, uma vez que são identificadas como homossexuais e não agradam aos olhares do sexo masculino.

As falas de pessoas idosas são reveladoras:

Eu queria fazer ginástica na academia. Mas, não dá! Eu não me sinto bem, os jovens colocam a música muito alta, é muito barulho. Acho que não é ambiente prá mim. (sexo feminino, 68 anos de idade).

Olha, eu já tentei fazer, tentei entrar na academia. O que acontece é que o professor não te olha, né? Ele só dá atenção as menininhas. (sexo feminino, 67 anos de idade).

Neste sentido, o que se percebe é que os corpos envelhecidos, os quais poderiam beneficiar-se da prática regular de exercícios físicos são aqueles que têm menor condição de compensação, uma vez que parecem alijados do processo (Stepansky, 1999).

Situação semelhante passa o obeso:

Eu me senti um estranho, por isso não fiquei muito tempo. Fica todo mundo te olhando. Eu sou gordo, né? Era diferente deles. Aquilo me incomodava aí eu saí fora. (sexo masculino, 45 anos de idade, obeso).

A classificação da obesidade normalmente é feita em função de percentual de gordura corporal que o indivíduo apresenta. O quadro 1 apresenta esta classificação, a partir de uma adaptação de Sichieri (1998).

Quadro 1. Classificação da quantidade de gordura corporal

\begin{tabular}{|l|c|c|}
\hline \multicolumn{1}{|c|}{ Classificação } & $\begin{array}{l}\text { Mulheres (em \% de } \\
\text { gordura) }\end{array}$ & $\begin{array}{l}\text { Homens (em \% de } \\
\text { gordura) }\end{array}$ \\
\hline I Magro severo & até 19 & até 10 \\
\hline 1 Magro moderado & 19,1 a 22 & 10,1 a 13 \\
\hline | Magro leve & 22,1 a 25 & 13,1 a 15 \\
\hline |Desejável & 25,1 a 30 & 15,1, a20 \\
\hline 1 Sobrepeso 1 & 30,1 a 35 & 20,1 a 25 \\
\hline | Sobrepeso II & 35,1 a 40 & 25,1 a 30 \\
\hline 1 Sobrepeso III & acima de 40 & acima de 30 \\
\hline
\end{tabular}


Os resultados apresentados pelo levantamento indicam que as academias também não são espaços para os obesos. Do total investigado, 3.526 individuos $(64,61 \%)$ estão classificados como magros ou condição desejável. Acima das condições desejáveis foram identificados 1.931 indivíduos (35,38\%). A tabela 3 apresenta estes dados:

Tabela 3. Distribuição do número de indivíduos que estão entrando nas academias de ginástica, em função da classificação do quantidade de gordura corporal

\begin{tabular}{|c|c|c|c|c|c|c|}
\hline \multirow[b]{2}{*}{ Classificação } & \multicolumn{2}{|c|}{ Total } & \multicolumn{2}{|c|}{ Masculino } & \multicolumn{2}{|c|}{ Feminino } \\
\hline & $\mathrm{n}$ & $\%$ & $\mathrm{n}$ & $\%$ & $\mathbf{n}$ & $\%$ \\
\hline Magro severo & 446 & 8,2 & 211 & 9,4 & 235 & $\overline{7,3}$ \\
\hline Magro moderado & 610 & 11,2 & 246 & 11,0 & 364 & 11,3 \\
\hline Magro leve & 730 & 13,4 & 248 & 11,1 & 482 & 15,0 \\
\hline Desejável & 1740 & 31,9 & 684 & 30,6 & 1056 & 32,8 \\
\hline Sobrepeso I & 1273 & 23,3 & 553 & 24,8 & 720 & 22,3 \\
\hline Sobrepeso II & 513 & 9,4 & 223 & 10,0 & 290 & 9,0 \\
\hline Sobrepeso III & 145 & 2,7 & 69 & 3,1 & 76 & 2,4 \\
\hline Total & 5.457 & & 2.234 & & 3.223 & \\
\hline
\end{tabular}

A situação referente ao histórico de doenças hipocinéticas também não é diferente. Do total investigado $5.201(95,3 \%)$ não apresentavam nenhuma doença. Os $256(4,70 \%)$ restantes apresentavam histórico de diabetes, hipertensão, doença arterial coronariana e osteoporose, muito abaixo dos valores encontrados na sociedade.

\section{Comportamentos de risco ou vulnerabilidade? À guisa de conclusão}

A noção de fator de risco, por outro lado, significa em última instância as circunstâncias do ambiente ou as características pessoais que conferem a um dado indivíduo a maior probabilidade matemática para o desenvolvimento de determinada doença (Pereira, 1995). Deste modo, as chances de adoecimento po-

Movimento Porto Alegre, v.9, n. 3, p.83-100, set./dez. de 2003 
deriam ser calculadas mediante aplicação da ferramenta epidemiológica.

Contudo, é possível empreender uma apreciação crítica, cujo foco não se concentra no biológico, ou nas relações de causas e efeitos, mas, antes, na vulnerabilidade do coletivo e do indivíduo. As atitudes pessoais, muitas vezes, são mediadas por situações onde a escolha é difícil. Isto pode estar provocando uma situação de vulnerabilidade, isto é, de enfraquecimento, de impossibilidade de reação.

Tratar de "comportamentos de risco" é, em última instância culpar o indivíduo por seu estado de "má saúde". Quando de'fato se observa com atenção e cuidado, talvez se possa apreender uma outra noção do que realmente leva a estas atitudes. A falta de renda, o excesso de trabalho, as condições climáticas, a violência urbana, a discriminação, etc. são alguns dos; fatores que podem, estar contribuindo para maior vulnerabilidade de determinados grupos sociais.

Reflexiones a cerca de la adhesión a los ejercicios físicos:
comportamientos de riesgo o vulnerabilidad? Resumen: El
objetivo del presente estudio fue reflexionar sobre las
relaciones entre el estado de vulnerabilidad y la adhesión a los
ejercicios físicos en la ciudad de Rio de Janeiro, Para eso,
fueron levantados datos sobre las características de 5.457
individuos que procuraron e iniciaron ejercicios físicos en
gimnasios; datos referentes a la condición de miseria de la
ciudad; y datos referidos ao índice de Desarrollo Humano de
laciudad de Rio de Janeiro. Además, fueron entrevistados siete
individuos, siendo dos obesos, dos com histórico de
enfermedad cardiovascular y tres personas de tercera edad.
Los resultados muestran que más de que un comportamiento
de riesgo, las personas pueden estar en una situación de
vulnaribilidad, donde no consiguen adherir a la práctica de
ejercicios físicos. Palabras-clave: Vulnerabilidad,
Comportamiento de Riesgo, Adhesión a los Ejercicios Físicos.

Movimento Porto Alegre, v.9, n. 3, p.83-100, set./dez. de 2003 
Reflections on physical activity adherence: risk behavior or vulnerability?

Abstract: The aim of this study was to reflect on the vulnerability status and adherence of physical activity in Rio de Janeiro. The subjects were 5,457 individuals who had looked for and started physical activity in fitness centers. Additional data on the poverty in Rio de Janeiro were gathered and figures borne out by the "Human Development Index" for the city were also taken into account. In addition, seven participants were interviewed: two were obese, two had a history of heart disease and three were senior citizens. The results have pointed out that, apart from being faced with a risk factor, people could be vulnerable whenever they cannot take on physical activity.

Keywords: Vulnerability, Risk Behavior, Physical Activity Adherence.

\section{Referências}

AYRES, J. R. C. M.; FRANÇA Jr., I.; CALAZANS, G. J.; SALETTI FILHO, H. C. O conceito de vulnerabilidade e as práticas de saúde: novas perspectivas e desafios. In: Promoção da saúde: conceitos, reflexões, tendências (Dina Czeresnia e Carlos Machado de Freitas, orgs.). Rio de Janeiro: Fiocruz, 2003, pp. 117-139.

BAUMAN, Z. O mal-estar da pós-modernidade. Rio de Janeiro: Jorge Zahar, 1998.

BERLIN, J. et ai. A meta-analysis of physical activity in the prevention of coronary heart disease. American Journal of Epidemiology. 132: 639-646, 1990.

CDC. Physical activity levels among children aged 9-13 years/ United States, 2002. MMWR. 52(33): 785-788, 2003.

CRAIG, CL. et al. Exploring the effect of the environment on physical activity: a study examining walking to work. American Journal of Preventive Medicine. 23(2S): 36-43, 2002.

DELOR, F \& HUBERT M. Revisiting the concept of 'vulnerability'. Social, Science \& Medicine. 50: 1557-1570, 2000.

DEMO, R Charme da exclusão social. Campinas: Autores Associados, 1998.

DUPAS, G. Economia global e exclusão social: pobreza, emprego, estado e o futuro do capitalismo. São Paulo: Paz e Terra, 1999.

Movimento Porto Alegre, v.9, n. 3, p.83-100, set./dez. de 2003 
GOLDBERG, M. Este obscuro objeto da epidemiología. In: Epidemiología: teoria e objeto (D. Czeresnia Costa, org.). São Paulo: Hucitec-Ábrasco, 1994, pp. 87-136.

HORLICK-JONES, T Patterns of risk and patterns of vulnerability. In: Workshop on emergency management (A. Amendola \& B. DeMarchi, orgs.). Ispra: Joint Research Centre, 1992, pp. 113-125.

IBGE. Mapa do fim da fome. Rio de Janeiro: IBGE, 2003.

KAPLAN, G.A. People and places: contrasting perspectives on the association between social class and health. International Journal of Health Services. 26(3): 507-519, 1996.

KURZ, R. Os últimos combates. Petrópolis: Vozes, 1997.

MALYSSE, S. Em busca dos (H)alteres-ego: olhares franceses nos bastidores da corpolatria carioca. In: Nu \& vestido: dez antropólogos revelam a cultura do corpo carioca (M. Goldenberg, org.). Rio de Janeiro: Record, 2002, pp. 79-137.

MANN, J.; TARANTOLA, D.J.M. \& NETTER, T.W. A AIDS no mundo. Rio de Janeiro: Relume Dumará/ABIA/IMS/UERJ, 1993.

NAVARRO, V. Neoliberalism, "Globalization", unemployment, inequalities, and the welfare state. International Journal of Health Services. 28(4): 607-682, 1998.

O GLOBO. Retratos do Rio. Rio de Janeiro, 24 de março de 2001.

PAFFENBARGER, R. et al. Physical activity, all-cause mortality, and longevity of college alumni. New England Journal of Medicine. 314: 605-613, 1986.

PATE, R. et al. Physical activity and public health: a recommendation from the centers for disease control and prevention and the American College of Sports Medicine. JAMA. 273(5): 402-407, 1995.

PEREIRA, M.G. Epidemiología: teoria e prática. Rio de Janeiro: Guanabara Koogan, 1995.

POCHMANN, M. e AMORIM, R. Atlas da exclusão social no Brasil. São Paulo: Cortez, 2003.

PROGRAMA AGITA SÃO PAULO. São Paulo, 1998.

SABINO, C. Anabolizantes: drogas de Apolo. In: Nu \& vestido: dez antropólogos revelam a cultura do corpo carioca (M. Goldenberg, org.). Rio de Janeiro: Record, 2002, pp. 139-188.

SANTOS, B.S. Pela mão de Alice: o social e o político na pós-modernidade. São Paulo: Cortez, 1999.

SOCHIERI, R. Epidemiología da obesidade. Rio de Janeiro: Eduerj, 1998.

STEPANSKY, D. Velhice, imaginário e velhice. In: Que corpo é esse?: novas perspectivas (N. Villaça; F. Góes e E. Kosovski, orgs.). Rio de Janeiro: Mauad, 1999, pp. 132-145.

SZWARCWALD, C; BASTOS, R; ESTEVES, M.; ANDRADE, C; PAEZ, M.; MEDICI, E. \& DERRICO, M. Desigualdade de renda e situação de saúde: o caso do Rio de Janeiro. Cadernos de Saúde Pública. 15(1): 15-28, 1999.

Movimento Porto Alegre, v.9, n. 3, p.83-100, set./dez. de 2003 
Recebido em: 28/09/2003

Aprovado em: 22/10/2003

\author{
Alexandre Palma \\ Rua José Veríssimo, 14 / 101, Méier \\ Rio de Janeiro, RJ \\ 20.720-180 \\ alexandrepalma@domain.com.br
}

Movimento Porto Alegre, v.9, n. 3, p.83-100, set./dez. de 2003 